\title{
Coronary thrombolysis with intravenous anisoylated plasminogen-streptokinase complex BRL 26921
}

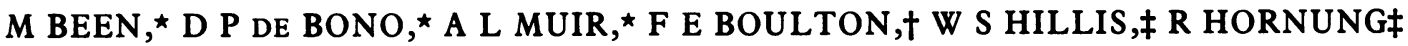 \\ From the ${ }^{\star}$ Departments of Cardiology and Medicine, Royal Infurmary of Edinburgh; the $\dagger$ Edinburgh Regional Blood \\ Transfusion Service, Edinburgh; and the $¥$ Department of Materia Medica, Stobhill General Hospital, Glasgow
}

SUMMARY BRL 26921 is a protected plasminogen-streptokinase complex with selective affinity for thrombus. When given intravenously within three hours of the onset of a first acute myocardial infarction angiographic patency of the infarct related vessel was seen in all 16 patients receiving the active drug compared with only two of 16 receiving a placebo. There was relative sparing of left ventricular function in the active treatment group with anterior infarction (mean left ventricular ejection fraction $37 \%$ compared with $23 \%$ for placebo), but no significant difference in left ventricular function between the active and placebo groups was seen in patients with inferior infarction.

Intravenous BRL 26921 is highly effective in causing coronary reperfusion and may help to preserve left ventricular function when given early in the course of anterior infarction.

Myocardial infarction is associated with thrombotic occlusion of a coronary artery in a high proportion of patients during the first few hours of its onset. ${ }^{1}$ Clinical studies have shown that reperfusion of previously occluded arteries is possible with thrombolytic agents and have suggested that infarct size may thus be limited. ${ }^{2} 3$ Early reperfusion is important as myocardial salvage decreases rapidly, though variably, with time. ${ }^{4}$

Thrombolytic agents may be given intravenously or by direct intracoronary infusion. Earlier studies with intravenous streptokinase were difficult to interpret because reperfusion was not assessed angiographically and because many studies allowed entry up to 12 or even 24 hours after infarction. More recent studies with angiographic verification of reperfusion and more restricted entry criteria have shown reperfusion rates of between $60 \%$ and $80 \% .^{56}$ Intravenous streptokinase infusion invariably causes systemic fibrinogenolysis and may produce a severe, albeit transient, haemorrhagic diathesis. Intracoronary administration of streptokinase is effective in producing thrombolysis but requires facilities for urgent cardiac catheterisation, which may well limit its applicability outside major cardiac centres. Moreover,

Requests for reprints to Dr D P de Bono, Department of Cardiology, The Royal Infirmary, Edinburgh EH3 9YW.

Accepted for publication 16 October 1984 despite the lower doses of streptokinase used systemic fibrinogenolysis remains a problem.

These disadvantages have led to a search for alternative thrombolytic agents ${ }^{7}$ and to the development of BRL 26921, ${ }^{8}$ a complex of streptokinase with anisoylated human plasminogen. The plasminogen selectively binds to fibrin rather than fibrinogen and causes the complex to seek out and bind to thrombus. Plasminogen is normally a potent activator of streptokinase, but to prevent premature activation while the complex is circulating it is temporarily inactivated by coupling an anisoyl group to its active site. This anisoyl group is removed by hydrolysis under in vivo conditions with a half life of approximately 37 minutes. After its removal, the streptokinase is activated and fibrinolysis occurs. In a previous study we showed that BRL 26921 was effective when given by the intracoronary route; in theory it should be equally effective if given intravenously.

The present study was designed to assess the efficacy and safety of intravenous BRL 26921 in causing coronary reperfusion and myocardial salvage when given within three hours of the onset of myocardial infarction.

\section{Patients and methods}

The study protocol was approved by the local ethical committee. Patients were considered for entry into the study if they gave a history typical of acute 
myocardial infarction, with chest pain of longer than 30 minutes' but less than three hours' duration, had ST elevation of $2 \mathrm{~mm}$ or more in at least two electrocardiographic leads, and were able to give informed consent.

Exclusion criteria were age $>70$ years, systolic blood pressure $<90 \mathrm{~mm} \mathrm{Hg}$ or $>200 \mathrm{~mm} \mathrm{Hg}$ at the time of dosing, previous cerebrovascular accident, active peptic ulcer within one year, any surgery within one month, menstruation, previous treatment with streptokinase, and previous transmural myocardial infarction.

\section{STUDY DESIGN}

The primary object of the trial was to determine whether intravenous BRL 26921 was more likely than placebo to produce patent coronary vessels on angiography 90 minutes after drug administration. Although early coronary angiography performed on patients taking a placebo is in our experience both safe and helpful in subsequent management, we felt obliged to answer this question using the smallest practicable number of patients. For this reason the study was designed as a paired sequential analysis trial. ${ }^{10}$ This is a well established technique for deciding whether an experimental treatment (BRL 26921) is significantly better than standard treatment using the minimum number of subjects. It involves trying each treatment alternately and scoring each pair of subjects as favourable to the experimental treatment, to standard treatment, or to neither. Pairs favourable to one or other treatment are plotted against the total number of pairs favourable (null pairs are ignored). The trial ends when the plot crosses one or other of two limit lines calculated from predetermined parameters. In the present study the parameters were set at $\alpha=0.025, \beta=0.2, u=3$, corresponding to a two tailed significance level of 0.05 , a power of $80 \%$, and an odds ratio of 3 or more in favour of the better process.

Randomisation was carried out independently at the two trial centres. The first step was to classify each patient as having an anterior infarct (ST elevation in leads V2, V3, or V4) or a non-anterior (inferior or lateral) infarct. Randomisation was carried out separately in these two groups to ensure equal numbers of active and placebo treatments. Treatment allocation was made using consecutively numbered vials of identical appearance containing either BRL 26921 (30 mg) or placebo (human serum albumin). Separate sets of vials were used for anterior and non-anterior infarct groups. There is a risk with this trial design of selection bias by guessing the next treatment allocation. We attempted to minimise this by randomising the order of active and placebo treatments within pairs and by leaving the decision to admit a patient to the study to an investigator who did not know the number of the vial to be used. We also checked retrospectively for comparability in patients allocated to active and placebo treatments and arranged for the double blind assessment of angiograms as described below.

As soon as possible after admission, a 19 gauge Venflon cannula was placed in a large peripheral vein for blood sampling and drug administration. Baseline samples of blood for measurements of coagulation factors, electrolyte concentration, and enzyme activities, and for blood grouping were taken. BRL 26921 or placebo was freshly reconstituted from freeze dried powder and given as a single intravenous injection. The initial $5 \mathrm{mg}$ was given over five minutes and the remaining $25 \mathrm{mg}$ over a further 10 minutes. Facilities for dealing with allergic reactions were available but were not in fact used. Blood was drawn for a repeat coagulation test one hour after dosing.

\section{Coronary arteriography}

Ninety minutes after the start of the BRL 26921 or placebo infusion coronary arteriography was performed in all patients using a procedure room within the coronary care unit, a portable image intensifier, and a videotape recorder. A 7 French gauge sheath was inserted percutaneously in the right femoral artery and arteriography was done by the Judkins's technique using non-ionic contrast medium (Niopam). Heparin was not used. For inferior infarcts the right coronary artery was injected first followed by the left coronary artery. For anterior infarcts the left coronary artery was injected first, followed in most patients by the right. At least two projections of each coronary artery were recorded. Results were classified as occlusions or reperfusions by a single observer who did not know which substance had been given and was not aware of the results of the coagulation test. As an additional safeguard, angiograms were reviewed retrospectively and in random order by an observer blind to patient identity to avoid the possibility of assessment bias from guessing the treatment given. The criterion for occlusion was an abruptly terminating stump of a major coronary vessel. The criterion for reperfusion was complete filling with contrast of the major coronary vessel in the infarct area within three cardiac cycles; almost invariably there was a severe proximal stenosis.

A prospective decision was made to give anticoagulants to all patients with reperfusion and withhold anticoagulants from all those with persistent coronary occlusion, irrespective of whether they had received BRL 26921 or placebo. The timing of introduction of heparin anticoagulation was based on the results of the one hour coagulation tests, repeated if necessary after four hours. Patients receiving anticoagulation treatment were given heparin by 
Table 1 Patient details, duration of symptoms, treatment received, and angiographic findings. For clarity patients are shown in pairs with placebo first.

\begin{tabular}{|c|c|c|c|c|c|}
\hline Case No & Sex & Age (yr) & $\begin{array}{l}\text { Time of onset to } \\
\text { treatment (hr) }\end{array}$ & Treatment & $\begin{array}{l}\text { Angiographic findings and reperfusion } \\
\text { classification }\end{array}$ \\
\hline $\begin{array}{r}1 \\
2 \\
3 \\
4 \\
5 \\
6 \\
7 \\
8 \\
9 \\
10 \\
11 \\
12 \\
13 \\
14 \\
15 \\
16 \\
17 \\
18\end{array}$ & $\begin{array}{l}\mathbf{F} \\
\mathbf{M} \\
\mathbf{M} \\
\mathbf{M} \\
\mathbf{M} \\
\mathbf{F} \\
\mathbf{M} \\
\mathbf{F} \\
\mathbf{M} \\
\mathbf{M} \\
\mathbf{M} \\
\mathbf{M} \\
\mathbf{M} \\
\mathbf{F} \\
\mathbf{M} \\
\mathbf{M} \\
\mathbf{F} \\
\mathbf{M}\end{array}$ & $\begin{array}{l}68 \\
56 \\
36 \\
64 \\
50 \\
66 \\
57 \\
65 \\
60 \\
46 \\
62 \\
43 \\
39 \\
61 \\
39 \\
71 \\
55 \\
49\end{array}$ & $\begin{array}{l}\text { Inferior infarct group } \\
2.5 \\
2.5 \\
2.75 \\
3.0 \\
3.0 \\
2.75 \\
3.0 \\
2.0 \\
1.25 \\
2.25 \\
3.0 \\
1.5 \\
2.0 \\
3.0 \\
2.25 \\
3.25 \\
1.75 \\
2.75\end{array}$ & $\begin{array}{l}\mathbf{P} \\
\mathbf{A} \\
\mathbf{P} \\
\mathbf{A} \\
\mathbf{P} \\
\mathbf{A} \\
\mathbf{P} \\
\mathbf{A} \\
\mathbf{P} \\
\mathbf{A} \\
\mathbf{P} \\
\mathbf{A} \\
\mathbf{P} \\
\mathbf{A} \\
\mathbf{P} \\
\mathbf{A} \\
\mathbf{P} \\
\mathbf{A}\end{array}$ & $\begin{array}{l}\text { Occluded RCA } \\
\text { Patent, stenosed RCA } \\
\text { Occluded RCA } \\
\text { Patent, stenosed RCA and Cx artery } \\
\text { Occluded Cx artery } \\
\text { Patent, stenosed RCA } \\
\text { Occluded RCA } \\
\text { Patent, stenosed RCA } \\
\text { Occluded RCA } \\
\text { Patent, stenosed RCA } \\
\text { Occluded RCA } \\
\text { Patent, stenosed RCA } \\
\text { Occluded Cx artery } \\
\text { Patent, mildly stenosed RCA } \\
\text { Occluded RCA } \\
\text { Patent, severely stenosed RCA } \\
\text { Occluded RCA } \\
\text { Patent, stenosed RCA and Cx artery }\end{array}$ \\
\hline $\begin{array}{l}19 \\
20 \\
21 \\
22 \\
23 \\
24 \\
25 \\
26 \\
27 \\
28 \\
29 \\
30 \\
31 \\
32\end{array}$ & $\begin{array}{l}\mathbf{M} \\
\mathbf{M} \\
\mathbf{M} \\
\mathbf{M} \\
\mathbf{M} \\
\mathbf{M} \\
\mathbf{M} \\
\mathbf{M} \\
\mathbf{M} \\
\mathbf{M} \\
\mathbf{M} \\
\mathbf{M} \\
\mathbf{M} \\
\mathbf{M}\end{array}$ & $\begin{array}{l}58 \\
51 \\
59 \\
47 \\
55 \\
54 \\
61 \\
50 \\
47 \\
67 \\
64 \\
56 \\
47 \\
43\end{array}$ & $\begin{array}{l}\text { Anterior infarct group } \\
3.0 \\
2.25 \\
2.5 \\
1.5 \\
2.75 \\
2.75 \\
2.25 \\
3.0 \\
3.0 \\
2.0 \\
3.25 \\
2.25 \\
2.75 \\
1.50\end{array}$ & $\begin{array}{l}\mathbf{P} \\
\mathbf{A} \\
\mathbf{P} \\
\mathbf{A} \\
\mathbf{P} \\
\mathbf{A} \\
\mathbf{P} \\
\mathbf{A} \\
\mathbf{P} \\
\mathbf{A} \\
\mathbf{P} \\
\mathbf{A} \\
\mathbf{P} \\
\mathbf{A}\end{array}$ & $\begin{array}{l}\text { Occluded LAD artery } \\
\text { Patent, LMS and three vessel disease } \\
\text { Occluded LAD artery } \\
\text { Patent, stenosed LAD artery } \\
\text { Occluded LAD artery } \\
\text { Patent, stenosed LAD artery } \\
\text { Occluded LAD artery } \\
\text { Patent, stenosed LAD artery } \\
\text { Occluded LAD artery } \\
\text { Patent, stenosed LAD artery } \\
\text { Patent, stenosed LAD artery } \\
\text { Patent, stenosed LAD, occluded RCA } \\
\text { Patent, stenosed Cx artery } \\
\text { Patent, stenosed LAD artery }\end{array}$ \\
\hline
\end{tabular}

A, active; P, placebo; RCA, right coronary artery; Cx, circumflex; LAD, left anterior descending; LMS, left main stem.

intravenous infusion pump at a rate sufficient to prolong the thrombin time by $50-100 \%$. Heparin was given for five days and followed with oral warfarin anticoagulation. The sheath was removed within 24 hours.

\section{Additional investigations}

Coagulation indices-Previous experience with this drug indicated that measurements of coagulation indices one hour after dosing gave values close to those of maximum effect. Fibrinolysis and fibrinogenolysis were assessed by measurement of the euglobulin clot lysis time and plasma fibrinogen concentration. Prothrombin time ratio, thrombin time, partial thromboplastin time, packed cell volume, and platelet count were also measured. Additional information was given by the plasma clotting time with reptilase (the reptilase time), ${ }^{11}$ which gives a direct measure of the anticoagulant effect of any fibrinogen degradation products on the coagulability of circulating fibrinogen.

Creatine kinase activity-Serial estimations were made of plasma creatine kinase activity at two hourly intervals for 24 hours.

Radionuclide ventriculography_Left ventricular function was assessed in all Edinburgh patients $(n=22)$ by gated blood pool radionuclide ventriculography in the left anterior oblique projection between the eighth and tenth day after admission. The person conducting the test was unaware of the treatment given. Results were analysed separately for anterior and non-anterior infarct groups. Statistical comparison was by an appropriate non-parametric test (Mann Whitney U test).

\section{Results}

Table 1 shows patient details, treatment received, and angiographic findings. A total of 35 patients were seen who fulfilled the entry criteria and were offered participation in the trial. Three patients declined admission to the study and received standard treatment. Twenty two patients were studied in Edinburgh (10 with anterior and 12 with inferior infarcts) and 10 in Glasgow (four with anterior and six with inferior infarcts). There were equal numbers of patients receiving active treatment and placebo in each centre and in each group. All patients with anterior infarcts were male, and there were two female patients in both 


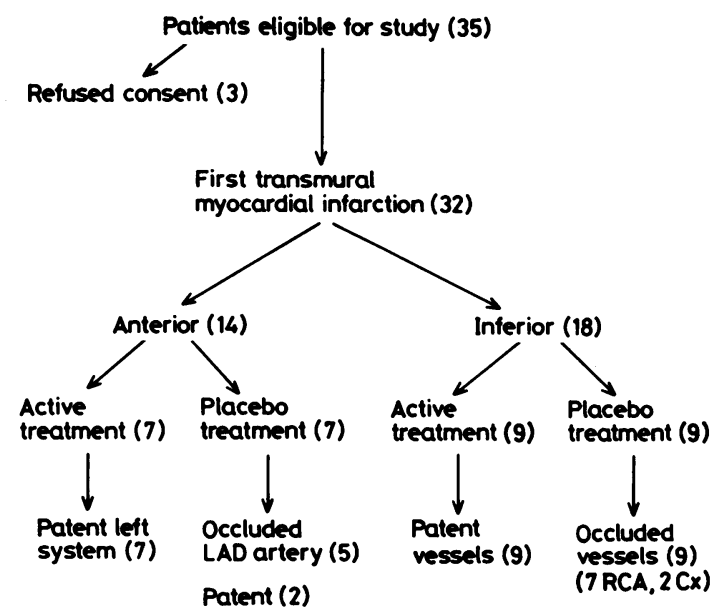

Fig. 1 Flow chart showing composition of trial. LAD, left anterior descending; $R C A$, right coronary artery; $C x$, circumflex (artery).

treatment groups with inferior infarcts. The mean age for those receiving active treatment was 58 (10) years (inferior) and $54(8)$ years (anterior) compared with 52 (11) years (inferior) and 56 (7) years (anterior) for the placebo group. The duration of chest pain before treatment was $2.4(0.6)$ hours and $2.6(0.5)$ hours for active and placebo groups respectively. There was no significant difference between active and placebo groups in terms of pulse rate, blood pressure, or signs of cardiac failure on admission to the study.

Figures 1 and 2 summarise the results.

\section{REPERFUSION}

In all patients receiving active treatment the vessel expected to be the cause of the infarction was patent at angiography. All but one of these patients had patency of all three major coronary vessels. Most patients had a severe stenosis in the presumed infarct related vessel, although the degree of stenosis was variable. Additional disease was seen in $50 \%$ of the patients, and one had a left main stem stenosis.

In the inferior infarct group receiving placebo seven patients had total occlusion of the right coronary artery and two of the left circumflex coronary artery - that is, nine occluded vessels in nine patients. Five of seven patients in the anterior placebo group had total occlusion of a left anterior descending vessel. In the remaining two patients early spontaneous reperfusion may have occurred.

\section{LEFT VENTRICULAR FUNCTION}

Radionuclide ventriculography performed 8 to 10 days after admission showed a variable pattern in the inferior infarct group, with a tendency to better left ventricular function in the active treatment group which did not reach statistical significance (ejection fraction $44(5) \%$ active, $40(8) \%$ placebo) (Table 2). There was an appreciable difference in the anterior infarct group, with an ejection fraction of $37(7) \%$ in those receiving active treatment compared with $23(5) \%$ in the placebo group $(\mathrm{p}<0.05$, Table 2$)$.

\section{CARDIAC ENZYME ACTIVITY}

All patients had a significant increase in plasma creatine kinase activity, signifying myocardial damage. The shape of the curve for serial measurements was appreciably different for the active and placebo groups, with a much earlier peak in the active group (Fig. 3).

\section{COAGULATION INDICES}

Changes in coagulation test results are shown in Table 3. The pretreatment coagulation test showed no major abnormality in any patient. The test results one hour after treatment showed no change in those who received placebo. Variable but significant changes in coagulation indices were seen in the active treatment group. Mean plasma fibrinogen concentrations fell from 3.1 to $1.2 \mathrm{~g} / \mathrm{dl}$. The mean reptilase time was prolonged from 19 to $51 \mathrm{~s}$ and the mean thrombin time from 11 to $38 \mathrm{~s}$.

\section{MORTALITY}

There were two late deaths, both in the placebo group.

Case 5-A 50 year old man with an inferior infarct

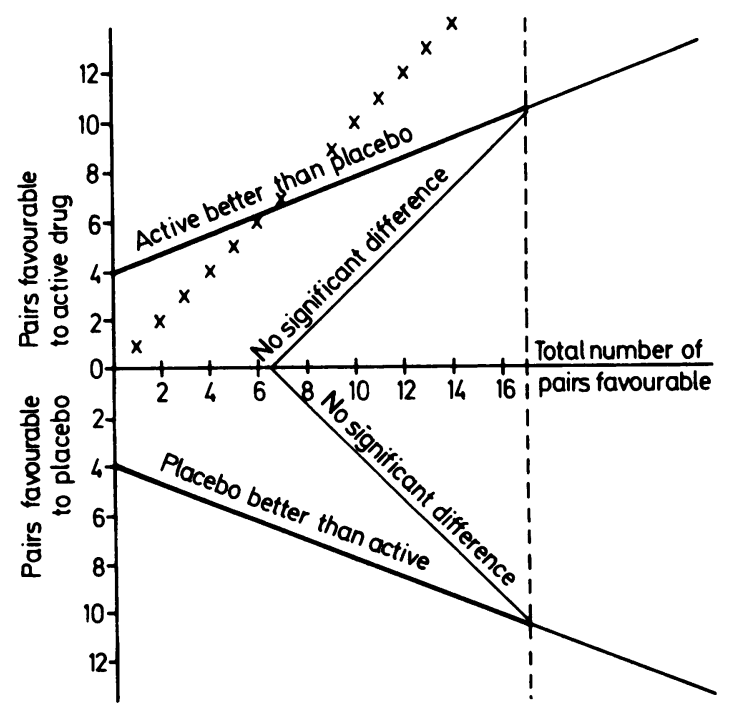

Fig. 2 Sequential analysis with respect to reperfusion. $\alpha$ was taken as 0.025 and $\beta$ as 0.2. $X$ indicates favourable pairs. 
Table 2 Individual and mean radionuclide left ventricular ejection fraction at 10 days in patients with anterior and inferior infarction receiving placebo or active treatment

\begin{tabular}{|c|c|c|c|}
\hline Case No & Active group & Case No & Placebo grouf \\
\hline $\begin{array}{l}20 \\
22 \\
24 \\
26 \\
28 \\
\text { Mean (SD) }\end{array}$ & $\begin{array}{l}48 \\
33 \\
38 \\
32 \\
33 \\
37(7)\end{array}$ & $\begin{array}{l}\text { infarction } \\
19 \\
21 \\
23 \\
25 \\
27 \\
\text { Mean (SD) }\end{array}$ & $\begin{array}{l}23 \\
28 \\
26 \\
29 \\
16 \\
24(5)\end{array}$ \\
\hline $\begin{array}{l}2 \\
4 \\
6 \\
8 \\
10 \\
12 \\
\text { Mean (SD) }\end{array}$ & $\begin{array}{l}35 \\
49 \\
42 \\
44 \\
47 \\
49 \\
44(5)\end{array}$ & $\begin{array}{l}\text { infarction } \\
1 \\
3 \\
5 \\
7 \\
9 \\
11 \\
\text { Mean (SD) }\end{array}$ & $\begin{array}{l}38 \\
45 \\
25 \\
49 \\
44 \\
38 \\
40(8)\end{array}$ \\
\hline
\end{tabular}

made good initial progress but subsequently developed left ventricular failure. Ejection fraction was $25 \%$. Ten days after admission he collapsed with ventricular fibrillation and could not be resuscitated.

Case 2-A 59 year old man with an anterior infarct had a straightfoward clinical course; left ventricular ejection fraction was $23 \%$. Three days after discharge ( 13 days after admission) he developed further chest pain. He did not seek immediate medical attention and died suddenly at home.

\section{HAEMORRHAGIC COMPLICATIONS}

There were two serious haemorrhagic complications and one minor complication. None was fatal.

Case 20-A man aged 51 with an anterior infarct received active treatment. Angiography showed all vessels to be patent, but there was three vessel coronary disease and left main stem stenosis. Treatment with heparin was started, and six hours later he vomited "coffee grounds" and became hypotensive. Heparin was withdrawn and blood transfusion restored his blood pressure. Endoscopy showed gastric erosions. Left ventricular ejection fraction was $48 \%$, and repeat angiography confirmed patency of all vessels. Coronary bypass grafting was successfully

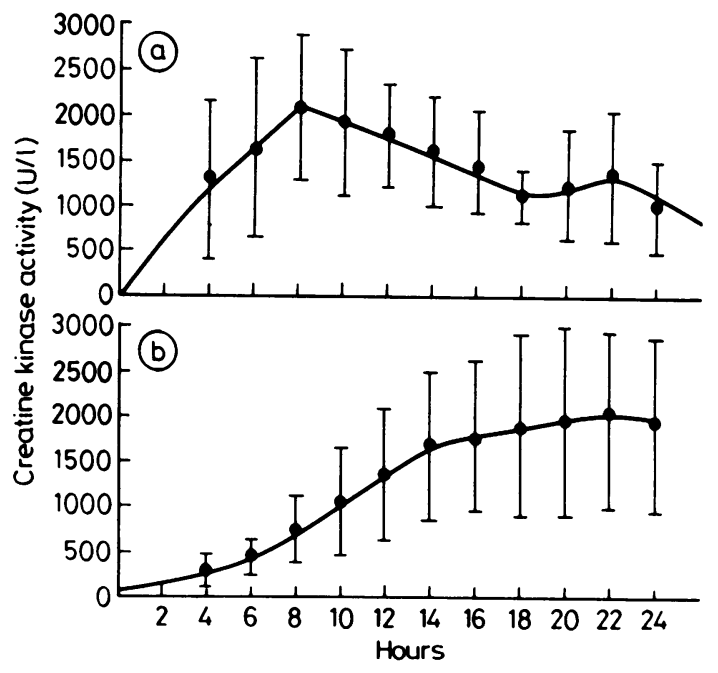

Fig. 3 Two hourly creatine kinase measurements in patients given (a) active treatment and (b) placebo.

performed 18 days after admission. Thirty years previously he had had a Polya gastrectomy for duodenal ulceration but had not subsequently complained of abdominal symptoms.

Case 8-A 65 year old woman collapsed at a bus stop with chest pain. On admission the electrocardiogram showed an inferior infarct, and she was also noted to have a small scalp laceration. She received active treatment. During the night after admission she became drowsy, and an emergency tomogram showed an intracerebral haematoma. Heparin was withdrawn, and the haematoma was evacuated surgically 34 hours after admission. She made a slow but complete neurological recovery.

Case 2-A 56 year old man with an inferior infarct received active treatment. Two days after angiography he developed a haematoma at the site of the femoral puncture. Heparin was withdrawn, and an hour later he complained of chest pain and showed further electrocardiographic changes and a further rise in cardiac enzyme activity. There were no sequelae.

Table 3 Coagulation indices before and one hour after administration of BRL 26921 (active) or placebo. Values are mean (SD)

\begin{tabular}{|c|c|c|c|c|}
\hline & \multicolumn{2}{|l|}{ Placebo } & \multicolumn{2}{|l|}{ Active } \\
\hline & Before & After & Before & After \\
\hline $\begin{array}{l}\text { Fibrinogen }(\mathrm{g} / \mathrm{dl}) \\
\text { Euglobulin lysis time }(\mathrm{min}) \\
\text { Prothrombin time ratio } \\
\text { Thrombin time } \\
\text { Partial thromboplastin time } \\
\text { Reptilase time } \star^{\star} \\
\text { Platelet count }\left(\times 10^{\star} / 1\right) \\
\text { Packed cell volume }(\%)\end{array}$ & $\begin{array}{l}2.8(0.9) \\
>200 \\
1.0(0 \cdot 1) \\
1(1) \\
-3(3) \\
0.4(0.7) \\
202(53) \\
45(2)\end{array}$ & $\begin{array}{l}3 \cdot 1(1 \cdot 0) \\
>270 \\
1.0(0 \cdot 1) \\
1(1) \\
3(2) \\
0.6(1.0) \\
212(39) \\
46(3)\end{array}$ & $\begin{array}{l}3 \cdot 1(0 \cdot 9) \\
>160 \\
1 \cdot 1(0 \cdot 1) \\
1(1) \\
5(8) \\
2 \cdot 7(2 \cdot 5) \\
253(55) \\
45(4)\end{array}$ & $\begin{array}{l}1 \cdot 2(0 \cdot 5) \\
6(7) \\
1.8(0 \cdot 4) \\
27(28) \\
61(71) \\
32(29) \\
261(58) \\
45(4)\end{array}$ \\
\hline
\end{tabular}

*Prolongation from control value in seconds. 
ARRHYTHMIAS

Arrhythmias within the first six hours of admission were more common in the active treatment group. In the placebo group sinus bradycardia with hypotension occurred in two patients (one requiring temporary atrial pacing), while frequent ventricular extrasystoles or short bursts of idioventricular rhythm occurred in a further three. In the active treatment group, one patient had an episode of ventricular fibrillation, two had idioventricular rhythm, one sinus bradycardia with hypotension, one atrioventricular dissociation, and one right bundle branch block. In addition, self terminating ventricular tachycardia occurred in three patients several hours after angiographically confirmed reperfusion.

\section{Discussion}

This study shows that BRL 26921 in a dose of $30 \mathrm{mg}$ is effective in causing reperfusion of occluded coronary arteries within 90 minutes of its administration. The finding of total coronary occlusion in all but two of the placebo group contrasts with that of coronary patency in all those receiving the active drug. The probability of this result arising by chance is very small (the confidence limit of $p<0.05$ from the sequential analysis chart is conservative; $\chi^{2}$ with Yates's correction $=21.7$, corresponding to $\mathrm{p}<0.001$ ).

BRL 26921 seems to cause less systemic defibrination than an equivalent dose of streptokinase. ${ }^{12}$ Any thrombolytic agent may, however, cause haemorrhage if the patient already has damaged vessels sealed only by thrombus, and this could have accounted for the serious bleeding complications in two of our patients. There was no correlation in the present study between bleeding complications and the extent of defibrination. One problem affecting both streptokinase and BRL 26921 is inactivation by circulating antistreptococcal antibodies. Because of the varying concentrations of these antibodies in the general population there is no uniformly applicable dose-response curve. In order to achieve an adequate amount of thrombolytic activity in the majority of patients we used a fairly large dose of $30 \mathrm{mg}$ BRL 26921, equivalent to 1.5 million units of streptokinase. This probably meant that some patients received a relative overdose, but there is as yet no rapid test for determining the titre of antistreptococcal antibodies to allow the individual dose to be tailored to the patient.

We believe that anticoagulation after reperfusion is important in maintaining patency of the reperfused vessel. Reinfarction in two of our patients was closely associated with cessation of anticoagulation, and we have seen a similar sequence in three other patients treated with BRL 26921 but not included in the pres- ent trial. The limited systemic lytic effect seen with this agent may actually be helpful in preventing reocclusion during the first few hours, but it may need to be supplemented with heparin.

The difference in effect on left ventricular ejection fraction between anterior and inferior infarction is not unexpected. Anterior infarction is well known to result in a greater reduction in left ventricular function than inferior infarction, and this accords with our finding of better preservation of left ventricular ejection fraction in the active anterior infarct group, while both active and placebo patients in the inferior infarct group had relatively well preserved ventricular function. Although our study group consisted only of patients with a first myocardial infarction the resting ejection fraction at 10 days was rather low in both active and placebo groups compared with the expected mean value of $36 \%$ based on the work of Dewhurst and Muir. ${ }^{13}$ Our entry criteria may have tended to select patients with more pronounced early electrocardiographic changes, more severe symptoms leading to earlier arrival in hospital, and hence larger potential infarcts.

Although the pattern of creatine kinase release with coronary reperfusion is altered, with a large early peak and rapid decline, the total amount of enzyme released is still thought to correlate with infarct size. ${ }^{14}$ In view of the altered shape of the curve in the group with reperfusion we did not feel confident about comparing the area under the curve for the two groups, as extrapolation on from 24 hours may be unreliable.

The numbers in this study are much too small to allow valid data on mortality. Patients who have survived for two or three hours after coronary occlusion are already to some extent "selected" for survival, and we further reduced expected mortality by excluding hypotensive patients. The association of prognosis with ejection fraction does, however, give cause for optimism. ${ }^{13}$ As yet the best treatment after reperfusion is unclear, and this is likely to influence long term results.

We believe that BRL 26921 is a significant advance in thrombolytic treatment in myocardial infarction. It is potentially widely available and can be given as an intravenous bolus with a high probability that reperfusion will occur within a reasonable time scale. With close attention to exclusion criteria complications can be kept to a minimum.

We thank Dr C Wathen for help with radionuclide ventriculography. Beecham Research Laboratories provided supplies of BRL 26921 and placebo, and we thank Drs G Harris and Maureen Elmslie for their support. 


\section{References}

1 DeWood MA, Spores J, Notske R, et al. Prevalence of total coronary occlusion during the early hours of transmural myocardial infarction. $N$ Engl f Med 1980; 303: 897-902.

2 Mathey DG, Kuck KH, Tilsner V, Krebber HJ, Bleifeld W. Non-surgical coronary recanalization in acute transmural myocardial infarction. Circulation 1981; 63: 48997.

3 Anderson JL, Marshall HW, Bray RE, et al. A randomized trial of intracoronary streptokinase in the treatment of acute myocardial infarction. $N$ Engl $\mathcal{Y}$ Med 1983; 308: 1312-8.

4 Jennings RB, Reimer MD. Factors involved in salvaging ischemic myocardium: effect of reperfusion of arterial blood. Circulation 1983; 68 (suppl I): 25-36.

5 Neuhaus KL, Tebbe U, Sauer C, Kreuzer H, Köstering $\mathrm{H}$. High dose intravenous streptokinase infusion in acute myocardial infarction [Abstract]. Eur Heart $\mathcal{F}$ 1984; 5 (suppl I): 24.

6 Rogers WJ, Wood WP Jr, Reeves RC, Whitlow PL. Intracoronary vs intravenous streptokinase in myocardial infarction [Abstract]. Eur Heart $\mathcal{F}$ 1984; 5 (suppl I): 24.
7 Marder VJ. Pharmacology of thrombolytic agents. Implications for therapy of coronary artery thrombosis. Circulation 1983; 68 (suppl I): 2-5.

8 Smith RAG, Dupe RJ, English PD, Green J. Fibrinolysis with acyl-enzymes: a new approach to thrombolytic therapy. Nature 1981; 290: 505-8.

9 Been M, de Bono DP, Boulton FE. Acute coronary thrombolysis with a single intracoronary ejection of BRL 26921 [Abstract]. Br Heart $\mathcal{F}$ 1984; 51: 679.

10 Armitage P. Restricted sequential procedures. Biometrika 1957; 44: 9-26.

11 Donati MB. The laboratory diagnosis of acquired defects of haemostasis. In: Thomson JM, ed. Blood coagulation and haemostasis. 2nd ed. Edinburgh: Churchill Livingstone, 1980: 189-90.

12 Cowley MJ, Hastillo A, Vetrovec GW, Hess ML. Effects of intra-coronary streptokinase in acute myocardial infarction. Am Heart $\mathcal{f} 1981$; 102: 1149-58.

13 Dewhurst NG, Muir AL. Comparative prognostic value of radionuclide ventriculography at rest and during exercise in 100 patients after first myocardial infarction. $\mathrm{Br}$ Heart f 1983; 49: 111-21.

14 Roberts R, Ishikawa MD. Enzymatic estimation of infarct size during reperfusion. Circulation 1983; 68 (suppl I): 83-9. 